\title{
SKAUSMO MALŠINIMO IKIHOSPITALINIAME ETAPE GALŪNIŲ TRAUMŲ ATVEJAIS TYRIMAS
}

\author{
Birutė Vabalaitė ${ }^{3}$ Ieva Paliokaite் ${ }^{1}$, Kęstutis Stašaitis ${ }^{1}$, Dinas Vaitkaitis ${ }^{2}$ \\ ${ }^{1}$ Lietuvos sveikatos mokslu universiteto Skubiosios medicinos klinika, ${ }^{2}$ Lietuvos sveikatos mokslu \\ universiteto Ekstremaliosios medicinos katedra, ${ }^{3}$ Lietuvos sveikatos mokslu universitetas
}

Raktažodžiai: skausmas, analgetikai, galūnių traumos, greitoji medicinos pagalba, skubiosios pagalbos skyrius.

\section{Santrauka}

Skausmas yra labai dažna priežastis, dèl kurios pacientai kreipiasi ị sveikatos priežiūros ịstaigas.Viena iš esminių problemų, neleidžiančių efektyviai gydyti skausmo, netinkamas skausmo vertinimas. Skausmas bus nepakankamai malšinamas jo stiprumą ịvertinus netinkamai arba skausmas bus negydomas, jei bus nediagnozuotas. Šio tyrimo rezultatai parodè, kad pacientų, patyrusių galūnių traumas, skausmo gydymas Všt Kauno miesto Greitosios medicinos pagalbos stotyje (GMP) ir Lietuvos sveikatos mokslų universiteto ligoninès Kauno klinikų Skubios pagalbos skyriaus (LSMUL KK SPS) yra skirtingas.

Tyrimo metodika. Atlikta darbuotojų, tirtų LSMUL KK SPS ir Kauno GMP stotyje, apklausa bei pacientų, atvežtų i LSMUL KK SPS 2015-2016 metais dèl galūnių skausmų (TLK S.40-99), GMP 110/A formų ịrašų ir SPS duomenų bazès analizè. Iš darbuotojų apklausos rinkti duomenys: amžius, darbo patirtis, lytis, pareigos, dažniausiai naudojamos skausmo skalès, o iš GMP 110/A formos bei SPS duomenų bazès - pacientų skausmo balų kitimas bei gydymas ikihospitaliniame etape.

Rezultatai ir išvados. Buvo apklausti 62 GMP ir 32 LSMUL KK Skubios pagalbos skyriaus darbuotojai. Iš GMP duomenų bazès buvo atrinkta 100 pacientų, 52 moterys (52\%) ir 48 vyrai (48\%), kurie skundèsi galūnių sužalojimais ar skausmais. Jų amžiaus vidurkis buvo $52,77 \pm 0,2$ metai.Iš apklausos paaiškèjo, kad tiek GMP $(58,1 \%)$, tiek SPS $(68,8 \%)$ darbuotojai skausmo balui vertinti dažniausiai naudoja skaitmeninę skausmo skalę. GMP darbuotojų minimalus skausmo balo vidurkis, kai skiriami ne- opioidiniai analgetikai, yra 2,68 $\pm 0,02$ balo, o SPS darbuotojų - 4,96 $\pm 0,04$ balo $(\mathrm{p}<0,05)$. Skausmo balų îvertinimai, atvežus pacientą ì prièmimo skyrių, tarp GMP ir SPS darbuotojų skyrèsi dvigubai: GMP pirmą kartą îvertino skausmą 2,57 $\pm 1,43$ balo, o SPS $-4,82 \pm 1,93$ balo. GMP darbuotojai skiria nesteroidinius vaistus nuo uždegimo ir opioidinius analgetikus esant mažesniam skausmo įvertinimui skausmo skalėse negu LSMUL KK SPS darbuotojai.

\section{İvadas}

Tarptautinè Skausmo Asociacija (The International Association for the Study of Pain) apibūdina skausmą kaip „nemalonų jutimą ir emocinị išgyvenimą", susijusị su tikru ar galimu audinių pažeidimu [1]. Skausmas yra labai dažna priežastis, dèl kurios pacientai kreipiasi ị sveikatos priežiūros įstaigas. Tikslus ir sistemingas skausmo įvertinimas lemia tikslią skausmo diagnozę ir efektyvų gydymą [1]. Nacionalinis sveikatos statistikos centras (National Center for Health Statistics) paskelbè, jog 46 milijonai amerikiečiu kasmet patiria ūminị chirurginį skausmą [2]. Anot Lietuvos skausmo draugijos prezidento dr. Arūno Ščiupoko, ,i prièmimą pas gydytoją ar į skubios pagalbos skyrius patenkantys pacientai $70 \%$ atvejų patiria skausmą". Užsienyje atlikti tyrimai rodo, kad daugiau kaip $75 \%$ pacientu i priemimo skyrių kreipiasi dèl skausmo, kuris yra trečioje vietoje pagal labiausiai paplitusią sveikatos problemą pasaulyje po véžio bei širdies ir kraujagyslių ligų [3]. Todèl galime teigti, jog skausmo problema išlieka aktuali ne tik Lietuvoje, bet ir už jos ribų.Norint spręsti šią problemą, būtina tinkamai ịvertinti ir efektyviai malšinti skausmą. Skausmo vertinimui yra dažniausiai naudojamos Skaitmeninè analogijos skausmo skalè (SAS), Vizualinė analogijos skalè (VAS), Žodinis ịvertinimas [2].

Viena iš esminių problemų, neleidžiančių efektyviai gydyti skausmo, yra netinkamas skausmo vertinimas. 
Skausmas bus nepakankamai malšinamas jo stiprumą įvertinus netinkamai arba skausmas bus negydomas, jei bus nediagnozuotas. Literatūros duomenimis, $78 \%$ pacientų, kurie kreipèsi ị prièmimo skyrių, jautè stiprų skausmą ir laiku negavo tinkamo nuskausminimo, tai tik įrodo, kad skausmo kontrole nepakankama skubios medicinos pagalbos metu. Dèl šios priežasties gydytojai neatsižvelgia i kiekvieno paciento skausmo stiprumą ir neužtikrinama jiems adekvataus nuskausminimo [4]. Skausmo gydymui naudojami medikamentai gali būti suskirstyti į 3 grupes: nesteroidiniai vaistai nuo uždegimo (NVNU), opioidiniai ir adjuvantiniai analgetikai [2]. Silpnas skausmas ( $0-4$ balai) turètų būti gydomas neopioidiniais analgetikais, vidutinio stiprumo (5-7 balai) - neopioidiniais analgetikais ir protarpiniu opioidų skyrimu, o stiprus skausmas (8-10 balai) - opioidiniais analgetikais [5], tačiau klinikinejje praktikoje dažnai šių rekomendacijų nesilaikoma.

Šis darbas buvo atliktas norint išsiaiškinti, kaip skausmą dèl galūnių traumų vertina Všt Kauno miesto Greitosios medicinos pagalbos bei Lietuvos sveikatos mokslų universiteto ligoninès Kauno klinikų Skubios pagalbos skyriaus darbuotojai ir kokiam skausmo balui esant, koks gydymas skiriamas.

Tyrimo tikslas: ištirti, kaip skausmo ịvertinimas susijęs su pacientų, patyrusių galūnių sužalojimus, skausmo gydymo efektyvumu teikiant skubią medicinos pagalbą.

\section{Tyrimo objektas ir metodika}

Tyrimas vyko 2015-2016 metais Lietuvos sveikatos mokslų universiteto (LSMU) ligoninès Kauno klinikų Skubios pagalbos skyriuje (toliau - SPS) ir Všt Kauno miesto Greitosios medicinos pagalbos (toliau - GMP) stotyje. Tyrimas vyko dviem etapais. Pirmame etape buvo pateiktos dvi anketinès apklausos formos SPS ir GMP darbuotojams, kurie atsakingi už pacientų skausmo ịvertinimą. Anketose buvo užduodami tokie klausimai: darbo patirtis, pareigos, amžius, kokias skausmo skales žino ir kokias dažniausiai naudoja savo praktikoje, kokia yra maksimali ir minimali SAS verte, kokia yra minimali verte, kai skiria analgetikus ir opioidus. Tiriamoji imtis visi - 32 SPS darbuotojai (slaugytojai ir paramedikai) ir visi vienos pamainos 62 GMP darbuotojai (slaugytojai, paramedikai ir gydytojai) apklausti atvykus ị įstaigą. Antrame etape buvo analizuojama GMP ir SPS duomenų bazių informacija. Atrinkti pacientai, patyrę galūnių sužalojimus (TLK kodas S.40-99). Išskirti duomenys apie skausmo balo įvertinimą bei jo kitimą nuo GMP atvykimo pradžios iki pristatymo į LSMUL KK Skubios pagalbos skyrių ir skausmo gydymą priklausomai nuo skausmo intensyvumo. Buvo lyginama, kaip skiriasi GMP darbuotojų ir SPS slaugytojų skausmo balo įverti- nimas atvežus pacientus ị prièmimo skyrių ir juos skirstant ligoninejje. Imties tūris apskaičiuotas atsižvelgiant ị $2014 \mathrm{~m}$. LSMUL KK SPS atlikto tyrimo apie ūminio pilvo skausmo vertinimo skirtumus [6] tarp gydytojų ir slaugytojų, kuriame gydytojai skausmo skalëje nurode 0,5 balais mažesnį skausmo intensyvumo balą nei slaugytojai. Daryta prielaida, kad panašaus skausmo vertinimo skirtumo galima tikètis ir mūsų tyrime bei esant pirmos rūšies klaidos tikimybei $\alpha=0,05$, antros rūšies klaidos tikimybè $\beta=0,20$ (tyrimo jèga $=0,80$ ), apskaičiuota tyrimo imtis -76 pacientai. Buvo peržiūrèta 100 Kauno miesto GMP 110/A formos įrašų ir atitinkamai toks pats skaičius LSMUL priėmimo skyriaus slaugytojų skausmo balo įvertinimų, kurie buvo lyginami tarpusavyje. Aprašomoji duomenu analizè buvo atlikta naudojantis SPSS 23.0 (Statistical Package for Social Sciences 13.0 for Windows) statistine programa. Analizei buvo naudojamos skaitinės duomenų charakteristikos, aprašomoji statistika bei požymių nepriklausomybès - $\chi^{2}$ kriterijus. Tikrinant hipotezę apie vidurkių lygybę dviejų grupių atveju buvo taikytas Stjudent'o (t) - testas. Reikšmingumo lygis vertintas kai $\mathrm{p}<0,05$.

\section{Rezultatai}

Buvo apklausti 62 GMP darbuotojai, kurių amžiaus vidurkis $46,70 \pm 12,88$ metai. Jie pagal pareigas pasiskirste taip: 32 slaugytojos $(51,61 \%), 15$ paramediku $(24,19 \%)$, 15 gydytojų (24,19\%). Taip pat buvo apklausti 32 LSMUL KK Skubios pagalbos skyriaus darbuotojai, kurių amžiaus vidurkis $34,81 \pm 8,25$ metai. Iš visų prièmimo darbuotojų $24(75 \%)$ buvo slaugytojos ir 8 paramedikai (25\%). Iš GMP darbuotojų 9 buvo vyrai $(14,52 \%)$, o 53 - moterys $(85,48 \%)$; iš SPS darbuotojų - 4 vyrai $(12,5 \%)$ ir 28 moterys $(87,5 \%)$. GMP darbuotojų darbo patirtis metais $-20,95$ $\pm 13,41$ metai, o SPS darbuotoju $-11,30 \pm 10,19$ metai. Iš apklausos paaiškèjo, kad tiek GMP $(58,1 \%)$, tiek SPS $(68,8 \%)$ darbuotojai skausmo balui vertinti dažniausiai naudoja skaitmeninę skausmo skalę.

Analizuota, koks yra GMP ir SPS darbuotojų minimalus balas kai skiria neopioidinius ir opioidinius analgetikus, palyginta, ar skiriasi vaistų skyrimas tarp skirtingų sveikatos priežiūros įstaigų ikihospitaliniame etape. Gauti duomenys parodè, kad GMP darbuotojų minimalus skausmo balo vidurkis, kai skiriami neopioidiniai analgetikai, yra 2,68 $\pm 0,02$ balo, o SPS darbuotojų - 4,96 $\pm 0,04$ balo $(p<0,05)$. Grafike matyti nuskausminamujų skyrimo skirtumai tarp abiejų sveikatos priežiūros įstaigų darbuotojų (1 pav.).

Apklausus, koks yra minimalus skausmo balas, kuomet skiriami opioidiniai analgetikai, GMP darbuotojai atsake, kad opioidus skiria prie 5,97 $\pm 0,02$ balo, o SPS responden- 
tai - 7,93 $\pm 0,03$ balo $(p<0,05)$. Šie duomenys parodè, kad opioidiniu analagetikų skyrimas priklausomai nuo skausmo balo taip pat skiriasi tarp Greitosios medicinos pagalbos ir Prièmimo skyriaus darbuotoju (2 pav.).

Iš GMP duomenų bazès buvo atrinkta 100 pacientų, 52 moterys $(52 \%)$ ir 48 vyrai (48\%), kurie skundèsi galūnių sužalojimais ar

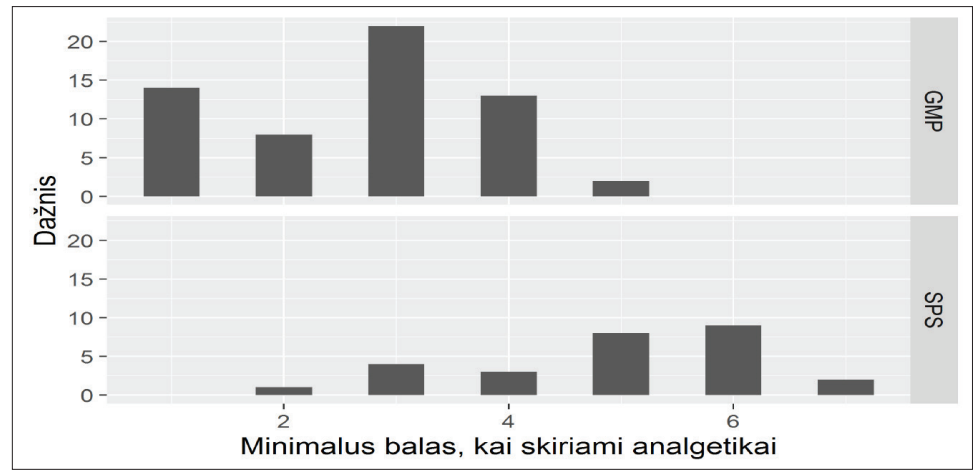

1 pav. Minimali skausmo balo vertè, kai GMP ir SPS darbuotojai skiria neopioidinius analgetikus

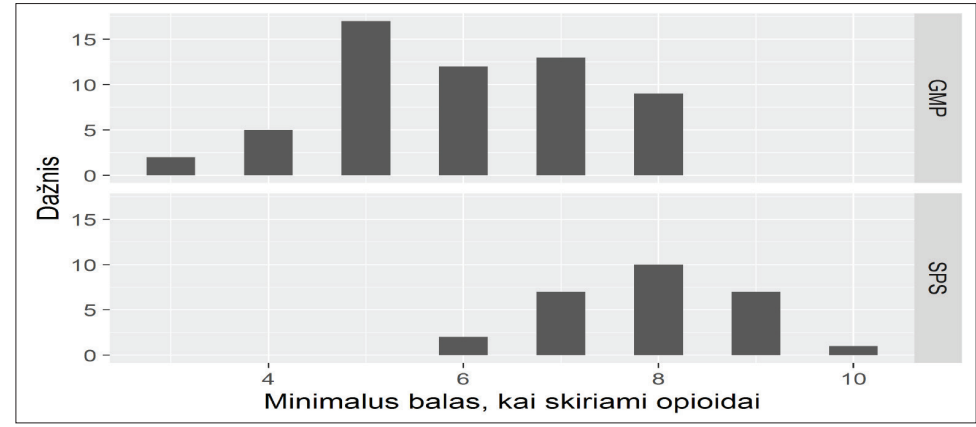

2 pav. Minimali skausmo balo vertè, kai GMP ir SPS darbuotojai skiria opioidinius analgetikus

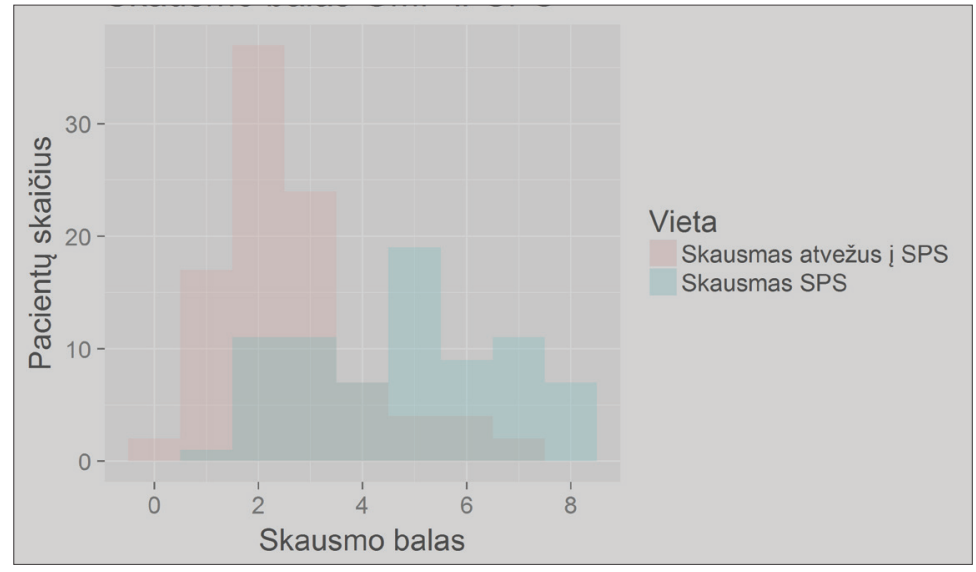

3 pav. Skausmo balo vertinimo skirtumai tarp GMP ir SPS darbuotoju skausmais. Jų amžiaus vidurkis buvo $52,77 \pm 0,2$ metai. Moterų amžiaus vidurkis $59,13 \pm 0,39$ metai, vyru $-45,88 \pm 0,38$ metai. GMP darbuotojai, atvykę ì îvykio vietą, vertino skausmo balą, kurio vidurkis buvo 3,44 $\pm 2,11$ balo, o pakartotinai ivertinus skausmą, atvežus pacientus ị LSMUL KK SPS, skausmo balas buvo $2,57 \pm 1,43$ balo $(\mathrm{p}<0,05)$. Iš visu 100 pacientų GMP darbuotojai NVNU skyrė $70 \%$ pacientu, opioidus - 7\% pacientų, o $23 \%$ pacientų gydymas nebuvo skirtas. Gydymas pagal skausmo balus pasiskirste taip: esant skausmo balui nuo 0 iki 3, 65,08\% atvejų buvo skirti NVNU, 33,33\% - nieko neskirta, $1,59 \%$ - opioidai; esant skausmo balui nuo 3 iki 6, 92,31\% atveju buvo skirti NVNU, 3,85\% opioidai ir 3,85\% - nieko neskirta; esant skausmo balui nuo 6 iki 10, 45,45\% atvejų buvo skirti NVNU, $45,45 \%$ - opioidai, 9,1\% - nieko neskirta. SPS darbuotojai skirstydami pakartotinai vertino skausmo balą ir jo vidurkis buvo 4,82 $\pm 1,93$ balai. Pacientų skausmo ịvertinimas GMP darbuotojų, pacientą atvežus ị prièmimo skyrių, statistiškai reikšmingai skyrèsi nuo SPS darbuotoju ivertinimo $(\mathrm{p}<0,05)(3$ pav. $)$.

\section{Diskusija}

Skausmas yra viena iš dažniausių priežasčių, dèl kurių pacientai kreipiasi pagalbos ị greitosios medicinos pagalbos ar prièmimo skyriaus medikus. Ypač jaučiamas ūminis skausmas turi neigiamą fiziologinę ir psichologinę ịtaką [7], tačiau vis dar yra nepakankamai malšinamas prièmimo skyriuose [8]. Šis tyrimas parode, kad pacientai, besiskundžiantys ịvairiais galūnių skausmais, pirmiausia yra nuskausminami GMP darbuotojų, tačiau pakartotinai SPS ịvertinus skausmo balą jis išlieka toks pats arba yra didesnis. Tarp šių dviejų tiriamuju grupių skyrèsi ir nuskausminamujų skyrimas: GMP darbuotojai skiria neopioidinius bei opioidinius nuskausminamuosius esant mažesniam skausmo ịvertinimui skalèse nei SPS darbuotojai. Galima manyti, jog skiriamas gydymas yra neadekvatus jaučiamam skausmui arba ženkliai skiriasi GMP ir SPS darbuotojų skausmo vertinimo principai.Mūsų tyrimo rezultatai panašūs kaip ir užsienio studijose:skausmas yra nepakankamai adekvačiai malšinamas Jungtinių Amerikos Valstiju prièmimo skyriuose $[9,10]$, blogai kontroliuojamas pakeliui ị ligoninę Australijoje [11].Oligoanalgezijos problema ikihospitalinia- 
me etape ir Skubiosios pagalbos skyriuje išlieka didele ne tik Lietuvoje, bet ir visame pasaulyje. Mūsų duomenimis, minimali skausmo verte, kai GMP darbuotojai skyre neopioidinius analgetikus, buvo 2,68 $\pm 0,02$ balai, o SPS darbuotojai - 4,96 $\pm 0,04$ balo. Palyginus su Vakarų valstybèmis, kur taip pat tik maža dalis pacientų, besiskundžiančių vidutiniu ar stipriu skausmu, gauna nuskausminamuosius [13], ar Prancūzija, kur net trys ketvirtadaliai pacientų po galūnių traumų negauna nuskausminamujų [12], situacija Lietuvoje neatrodo prastesne, tačiau tuo pacientų paguosti negalime. Austrijos tyrimai rodo, kad greitosios medicinos pagalbos teikejai gerokai nuvertina pacientų patiriamą skausmą ir net $92 \%$ pacientų buvo skirti opioidiniai analgetikai pakeliui ị ligoninę, nors jie ir neatitiko skausmo balo [14]. Tiriant skausmo gydymą Norvegijos skubios pagalbos skyriuje buvo nustatyta, jog pacientams, kurie skundèsi vidutinio stiprumo ar stipriu skausmu (58\%), tik $14 \%$ iš jų buvo skirtas gydymas analgetikais [15]. Visa tai tik įrodo, jog ikihospitalinio nuskausminimo problemą apima netinkamas skausmo ịvertinimas ar nuvertinimas, skirtinos per mažos nuskausminamujų dozės, kurios neatitinka skausmo balo, ar parenkami netinkami analgetikai. Skausmo valdymą ikihospitaliniame etape galètų pagerinti Džiaksonvilio (Florida, JAV) ligoninès Skubios pagalbos skyriaus 2016 m. išleistos naujos skausmo gydymo gairès[16]. Irodymais pagrịstų rekomendacijų ịdiegimas ir nuolatinis skubios pagalbos teikimo kokybės vertinimas galëtų reikšmingai padèti skausmą kenčiantiems pacientams.

\section{Išvados}

1. Skausmą dèl galūnių traumų greitosios medicinos pagalbos ir skubiosios pagalbos skyriaus medikai vertina skirtingai.Skausmo balų įvertinimai, atvežus pacientą i prièmimo skyrių, tarp Kauno miesto GMP ir SPS darbuotojų skyrèsi dvigubai: GMP pirmą kartą ịvertino skausmą 2,57 $\pm 1,43$ balo, o SPS $-4,82 \pm 1,93$ balo.

2. GMP darbuotojai skiria nesteroidinius vaistus nuo uždegimo ir opioidinius analgetikus esant mažesniam skausmo ịvertinimui skausmo skalèse negu LSMUL KK SPS darbuotojai.

\section{Literatūra}

1. Kishner S. Pain assessment: practice essentials, overview, Technique. 2016.

2. Wuhrman E, Cooney MF. Acute Pain: Assessment and Treatment. 2011.

3. Downey LV, Zun LS. Pain management in the emergency department and its relationship to patient satisfaction. 2010;3(4):326-30.

4. Sasnauskaitė A., Kubilius D., Petrikonis K., Ščiupokas A. Skaus- mo vertinimas teikant būtinąją pagalbą. Skausmo medicina 2006;1(14).

5. Pre-hospital pain management for adults, children, and special populations. University of Florida College of Medicine - Jacksonville Department of Emergency Medicine, Pain Management and Assessment Initiative (PAMI): A Patient Safety Project, [adaptuota pagal http://pami.emergency.med. jax.ufl.edu/]. 2016.

6. Stašaitis K. Ūminio pilvo skausmo klinikinių charakteristikų ir veiksnių, lemiančių efektyvų skausmo malšinimą, tyrimas. 2014; 71.

7. Macintyre PE, Walker SM. The scientific evidence for acute pain treatment. Curr Opin Anaesthesiol. 2010;23(5):623-8. doi: 10.1097/ACO.0b013e32833c33ed. [PubMed][Cross Ref]

8. Arendts G, Fry M. Factors associated with delay to opiate analgesia in emergency departments. J Pain. 2006;7(9):682-6. doi: 10.1016/j.jpain.2006.03.003. [PubMed][Cross Ref]

9. Grant PS. Analgesia delivery in the ED. American Journal of Emergency Medicine. 2006;24(7): 806-809.

https://doi.org/10.1016/j.ajem.2006.05.004

10. Miner J, Biros MH, Trainor A, Hubbard D, Beltram M. Patient and physician perceptions as risk factors for oligoanalgesia: a prospective observational study of the relief of pain in the emergency department. Acad Emerg Med 2006;13(2):140 - 6 [electronic publication 2006 Jan 25].

https://doi.org/10.1111/j.1553-2712.2006.tb01662.x

11. Dong L, Donaldson A, Metzger R, Keenan H. Analgesic administration in the emergency department for children requiring hospitalization for long-bone fracture. Pediatr Emerg Care. 2012;28:109-14.

https://doi.org/10.1097/pec.0b013e3182442c25

12. Thomas SH, Shewakramani S. Prehospital trauma analgesia. 2008; 35(1):47-57.

13. Gausche-Hill M, Brown KM, Oliver ZJ. et al. An evidencebased guideline for prehospital analgesia in trauma. Prehospital Emergency Care. 2013.

14. Luger TJ, Lederer W. et al. Acute pain is underassessed in outof- hospital emergencies. 2003;10(6).

15. Dale J, Bjørnsen LP. Assessment of pain in a Norwegian Emergency Department. Scand J Trauma Resusc Emerg Med. 2015;23(86).

https://doi.org/10.1186/s13049-015-0166-3

\section{PREHOSPITAL PAIN RELIEF IN CASE OF LIMB INJURY}

B. Vabalaitė, I. Paliokaitė, K. Stašaitis, D. Vaitkaitis

Key words: pain, analgesics, limb injuries, ambulance, emergency department.

Summary

Pain is one of the main reasons why people call for medical help. One of the major problems hindering the effective treatment of pain is an inadequate assessment of pain. The pain can not be 
properly managed without an accurate evaluation of its intensity as well as without treatment, once it is diagnosed. Aim of the study was to evaluate differences in pain assessment and treatment for patients who have suffered limb injuries, by staff of the Kaunas City Ambulance Service (AS) and the Emergency Department of the Hospital of the Lithuanian University of Health Sciences Kauno clinics (ED).

Methods. A survey of the staff of the ED and the AS was conducted, and the study of Forms 110/A provided by the AS as well as the ED data bases of the patients who were treated at the ED because of a limb pain in 2015-2016 (ICD codes S.40-99) was performed. The staff survey included the data about their age, work experience, gender, position, the most commonly used pain assessment scales. Forms 110/A and the ED data bases provided information about the changes in patients' pain scores and its treatment in the stage of pre-hospitalisation.

Results. 62 employees of the KAS and 32 employees of the Emergency Department were surveyed, and 100 patients who complained of limb pain were selected from data bases, 52 female (52 per cent) and 48 male (48 per cent). Their average age was 52.77 \pm 0.2 . The staff survey revealed that the most frequent method to evaluate the pain score used by both the AS staff (58.1 per cent) and the ED staff (68.8 per cent) is the digital pain assessment scale. When the AS staff evaluated the pain score for the first time, it was $2.57 \pm 1.43$. However, when the staff of the Emergency Department repeatedly evaluated the pain score, it was $4.82 \pm 1.93$. The AS staff administered non-opioid analgesics at a minimum average pain score of $2.68 \pm 0.02$, and the Emergency Department staff administered them at the pain score of $4.96 \pm 0.04(\mathrm{p}<0.05)$.

Conclusions. The intensity of the pain caused by limb injuries was scored differently by the staff of the Ambulance Service and the Emergency Department. Patients at the ED received two times higher pain score than in Ambulance Service (4.82 \pm 1.93 and 2.57 \pm 1.43 respectively). The staff of Ambulance Service administered nonsteroidalanti-inflammatory drugs and opioid analgetics at lower pain scores than the staff of the Emergency Department.

Correspondence to: vabirute@gmail.com

Gauta 2017-03-10 